\title{
Follicle-stimulating hormone is independently associated with lean mass but not BMD in younger postmenopausal women
}

\author{
Margaret L. Gourlay, MD, MPH ${ }^{1}$, Bonny L. Specker, $\mathrm{PhD}^{2}$, Chenxi Li, $\mathrm{PhD}^{3}$, Catherine A. \\ Hammett-Stabler, $\mathbf{P h D}^{4}$, Jordan B. Renner, $\mathbf{M D}^{5}$, and Janet E. Rubin, $\mathbf{M D}^{6}$ \\ ${ }^{1}$ Department of Family Medicine, University of North Carolina, Chapel Hill, NC \\ 2EA Martin Program in Human Nutrition, South Dakota State University, Brookings, SD \\ ${ }^{3}$ North Carolina Translational and Clinical Sciences Institute (Biostatistics), University of North \\ Carolina, Chapel Hill, NC \\ ${ }^{4}$ Department of Pathology and Laboratory Medicine, University of North Carolina, Chapel Hill, NC \\ ${ }^{5}$ Department of Radiology, University of North Carolina, Chapel Hill, NC \\ ${ }^{6}$ Medicine and Division of Endocrinology, University of North Carolina, Chapel Hill, NC
}

\begin{abstract}
Purpose-Increased follicle-stimulating hormone (FSH) has been associated with lower bone mineral density (BMD) in animal models and longitudinal studies of women, but a direct effect has not been demonstrated.
\end{abstract}

\begin{abstract}
Methods-We tested associations between FSH, non-bone body composition measures and BMD in 94 younger (aged 50 to 64 years) postmenopausal women without current use of hormone therapy, adjusting for sex hormone concentrations and clinical risk factors for osteoporosis. Lean mass, fat mass and areal BMD (aBMD) at the spine, femoral neck and total hip were measured using dual energy X-ray absorptiometry (DXA). Volumetric BMD (vBMD) was measured at the distal radius using peripheral quantitative computed tomography (pQCT). Results: FSH was inversely correlated with lean and fat mass, bioavailable estradiol, spine and hip aBMD, and vBMD at the ultradistal radius. In the multivariable analysis, FSH was independently associated with lean mass $(\beta=-0.099, p=0.005)$ after adjustment for age, race, years since menopause, bioavailable estradiol, bioavailable testosterone, LH, PTH, SHBG and urine N-telopeptide. FSH showed no statistically significant association with aBMD at any site or pQCT measures at the distal radius in adjusted models. Race was independently associated with aBMD, and race and urine $\mathrm{N}$-telopeptide were independently associated with bone area and vBMD.
\end{abstract}

Conclusions-After adjustment for hormonal measures and osteoporosis risk factors, higher concentrations of FSH were independently associated with lower lean mass, but not with BMD. Previously reported correlations between FSH and BMD might have been due to indirect associations via lean mass or weight.

(C) 2011 Elsevier Inc. All rights reserved.

Corresponding author: Margaret Gourlay, MD, MPH; Aycock Building; Manning Drive, CB \#7595; UNC-Chapel Hill; Chapel Hill, NC 27599-7595; Phone: (919)966-2843, Fax: (919)966-6125; margaret_gourlay@ med.unc.edu.

Publisher's Disclaimer: This is a PDF file of an unedited manuscript that has been accepted for publication. As a service to our customers we are providing this early version of the manuscript. The manuscript will undergo copyediting, typesetting, and review of the resulting proof before it is published in its final citable form. Please note that during the production process errors may be discovered which could affect the content, and all legal disclaimers that apply to the journal pertain. 


\section{Keywords}

bone mineral density; follicle-stimulating hormone; menopausal

\section{INTRODUCTION}

A 2006 study by Sun et al. suggested that high circulating levels of follicle-stimulating hormone (FSH) caused hypogonadal bone mineral density (BMD) loss in animal models [1]. Subsequent basic science [2] and clinical [3, 4] studies did not support an independent association between FSH and BMD, indicating that confounding factors might be responsible for correlations between FSH and bone mass. The role of non-bone body composition measures as possible confounders has not been investigated.

In a cross-sectional study of 10 normal-weight and 22 overweight or obese women with normal menstrual cycles referred to an obesity center for weight loss [5], De Pergola et al. demonstrated that FSH and luteinizing hormone were inversely associated with BMI independently of age, insulin levels, estradiol, and inhibin B. The authors interpreted these findings to mean that body mass may have an inhibitory effect on gonadotropin secretion. Sowers et al. followed 543 perimenopausal women annually over 6 years (15\% of cohort postmenopausal by sixth study visit) and found increasing FSH concentrations were associated with increasing fat mass and decreasing lean mass measured by bioelectrical impedance analysis [6]. Cannon et al. explored possible relationships among FSH, body fat percentage and BMD in a study of 30 pre- or perimenopausal women aged 20 to 50 [7]. They found that FSH concentrations were correlated with circulating concentrations of bone resorbing cytokines, and at least one cytokine marker was correlated with body fat percentage and plasma leptin, but not with BMD. Other investigators have demonstrated that lean and fat mass are strong independent determinants of BMD in postmenopausal women [8-12], and fat mass has been hypothesized to play a mediating role in the association of weight change and sex-hormone binding globulin with total hip BMD in women [8]. Studies clarifying relationships among FSH, non-bone body composition measures and BMD in postmenopausal women are lacking.

We previously conducted a cross-sectional study to test the association between serum FSH and measures of bone strength in 111 postmenopausal women aged 50 to 64 years [4]. In the multivariable analysis, weight and race were important determinants of BMD, while FSH, bioavailable estradiol and other hormonal variables did not show statistically significant associations with hip and spine areal BMD (aBMD) measured by dual-energy X-ray absorptiometry (DXA) and volumetric BMD (vBMD) measured by peripheral quantitative computed tomography (pQCT). Because of multicollinearity (strong correlations among explanatory variables in regression model) among weight, lean mass and fat mass, only weight could be studied as a correlate of BMD in our original analysis. We now propose to study relationships among FSH, lean and fat mass and BMD in younger postmenopausal women without current hormone therapy use. We hypothesize that FSH might be indirectly associated with BMD via lean mass or fat mass.

\section{METHODS}

\section{Study participants}

Participants were 94 community-dwelling postmenopausal women aged 50 to 64 years of mixed ethnic background (self-reported race) and without current hormone use, recruited between 2005 and 2010 from appointment rosters from primary care clinics at the University of North Carolina or from the community by university e-mail listservs, posters, and 
referrals by past study participants. Women were eligible for the study if they reported their last menstrual period to be over 12 months before the study visit. They were excluded if they were currently using hormone therapy (pills or transdermal), had ever taken an osteoporosis treatment agent (bisphosphonate, selective estrogen receptor modulator, calcitonin, teriparatide) or prescribed vitamin D or vitamin D derivative, had a contraindication to DXA or weighed greater than 305 pounds. Although there were no a priori laboratory criteria, one participant was excluded after she was found to have a serum estradiol level of 254 with no history of hormone use. Another enrolled participant could not be included in this analysis because phlebotomy to obtain her serum sample was unsuccessful. The research protocol was reviewed and approved by the Institutional Review Board of the University of North Carolina and the UNC Clinical Translational Research Center. Informed consent was obtained from all participants at the time of the study visit.

\section{Measurements}

Participants were instructed to fast and to urinate no more than once after midnight before attending a morning study visit in the UNC Clinical Translational Research Center. Serum and urine collection were completed before $10 \mathrm{AM}$, and bone imaging was completed while participants were fasting.

aBMD and non-bone body composition measures-aBMD was measured at the femoral neck, total femur and spine (L1-L4) in all participants by a trained and certified radiologic technologist using DXA (Hologic Discovery densitometer, Hologic, Inc., Bedford, MA). The technologist was blinded regarding the specific study hypothesis. Quality control was maintained by daily scanning of an anthropomorphic spine phantom. The coefficient of variation for the densitometer is $0.6 \%$ and the reference limits for variation are $+/-1.5 \%$. aBMD results were recorded in grams per square centimeter, and as T scores ([BMD of participant - mean BMD of reference population]/SD of BMD of reference population) based on Hologic reference norms for white and nonwhite women for the spine, total hip, femoral neck and distal radius.

Regional and whole body measurements of lean and fat mass were also obtained during the same DXA scan. A research radiologist (JBR) in the UNC Department of Radiology reviewed the DXA reports.

Peripheral QCT measures-We measured trabecular vBMD $(\mathrm{mg} / \mathrm{cm} 3)$ at the ultradistal (4\%) radius by pQCT using an XCT2000 scanner (Stratec, Orthometrix). Cortical area and vBMD were assessed at the $33 \%$ distal radius. The scans were analyzed at the distal site using contour mode 3 with a threshold of 169 to determine the outer edges of the bone, and peel mode 4 with a threshold of 650 and additional concentric peel of $10 \%$ to separate cortical bone from trabecular bone. For cortical analysis at the diaphyseal sites, we used bone-separation mode 2, and bone geometry threshold $710 \mathrm{mg} / \mathrm{cm} 3$ for area and vBMD.

Based on an analysis of the last 140 phantom scans performed on the XCT2000 sn-91255 at UNC between January 31, 2007 and January 14, 2010, the precision (average \% coefficient of variation for 4 slices) of the device for pQCT measurements was $0.43 \%$ for measures of trabecular bone density (analysis by Dan Schiferl, Bone Diagnostic Inc., January 22, 2010).

Biochemical analyses-Fasting serum was analyzed for FSH, luteinizing hormone (LH), estradiol (E2), bioavailable testosterone (bio T), thyroid stimulating hormone (TSH), parathyroid hormone (PTH), sex-hormone binding globulin (SHBG), bone specific alkaline phosphatase (BSAP), dehydroepiandrosterone sulfate (DHEAS) and serum 25-

hydroxyvitamin D (25-OHD) as previously described [4]. We used bioavailable (free or 
associated with albumin in the circulation) sex steroid concentrations because they better reflect the fractions of these factors available to tissues [13]. The bioavailable E2 (bio E2) concentration was calculated by multiplying the total E2 by the fraction that was non-SHBG bound as per Khosla et al. [13]. Urine N-telopeptide (NTx) and urine creatinine tests were processed at Mayo Medical Laboratories.

Other independent variables-Demographic information and risk factors for osteoporosis and fracture were assessed by trained research assistants. Anthropometric measurements were taken by a research nurse in the UNC Clinical Translational Research Center.

\section{Statistical analysis}

Descriptive statistics-In the univariate analysis, means and standard deviations were calculated for demographic and anthropomorphic measures, hormonal variables, weight, lean and fat mass, and DXA and pQCT measures. Spearman rank correlations, which are not sensitive to outliers, were used to analyze unadjusted relationships among FSH, bio E2, other independent variables and the outcomes.

\section{Multivariable analysis with non-bone body composition outcomes-Multiple} linear regression models were constructed using lean mass and fat mass as dependent variables. Possible covariates included age, race (nonwhite vs. white), years since menopause, ever use of hormone therapy, FSH, bio E2, bio T, LH, TSH, PTH, SHBG, BSAP, DHEA-S, serum 25-OHD and urine NTx). Age, race, FSH, bio E2 and bio T were included as independent variables in both models. To select the remaining independent variables, we used simple (single variable) linear regression to identify those independent variables with at least one $\mathrm{p}$ value less than 0.05 for unadjusted associations with the lean and fat mass outcomes, with backward selection to a maximum of 10 variables. Using this approach, the covariates selected for the lean and fat mass models were age, race, years since menopause, FSH, bio E2, bio T, LH, PTH, SHBG and urine NTx.

To test for multicollinearity of the explanatory variables in the models, variance inflation factors were calculated and ranged from 1.22 (years since menopause and PTH) to 3.41 (FSH) [VIF <10 indicates no extreme multicollinearity] for the final model with lean mass as the outcome, with identical results for the fat mass outcome. Results from the models were expressed in beta coefficients, which represent the mean change in the dependent variable for a 1 unit change in the independent variable, adjusted for the other covariates. For example, a beta coefficient ( $\beta$ ) of -0.079 for FSH vs. lean mass would mean for a 1-unit $(1 \mathrm{mIU} / \mathrm{ml})$ increase in $\mathrm{FSH}$, the lean mass was $0.079 \mathrm{~kg}$ lower, adjusted for the other independent variables in the model. Age and years since menopause were divided by 10 before inclusion in the models; after this transformation, a $\beta$ of -1.559 meant for a 10 -year increase in age, the fat mass was $1.559 \mathrm{~kg}$ lower, adjusted for the other independent variables. Race was coded as $0=$ nonwhite, $1=$ white; thus, $\beta<0$ for the race variable meant that bone density was lower in white women compared to nonwhite women.

Multivariable analysis with aBMD and PQCT outcomes-Separate multiple linear regression models were constructed for these dependent variables: $\mathrm{aBMD}\left(\mathrm{g} / \mathrm{cm}^{2}\right)$ at the spine, femoral neck and total hip; trabecular vBMD $\left(\mathrm{mg} / \mathrm{cm}^{3}\right)$ at the ultradistal radius, total bone area $(\mathrm{mm} 2)$, total $\mathrm{vBMD}$, cortical area and cortical $\mathrm{vBMD}$ at the $33 \%$ distal radius. The same potential covariates listed for the non-bone models, as well as lean mass and fat mass, were initially considered. Age, lean mass, fat mass, race, FSH, bio E2 and bio T were included as independent variables in all aBMD and pQCT models. Using a process similar to that described for the non-bone models, these other covariates were selected: LH, SHBG 
and urine NTx for the aBMD models; LH and urine NTx for the pQCT models. Variance inflation factors ranged from 1.21 (age) to 3.71 (FSH) for the final model with femoral neck aBMD as the outcome, with identical results for spine and hip aBMD. Variance inflation factors ranged from 1.16 (age) to 3.37 (FSH) for the full model with trabecular vBMD as the outcome, with very similar results for all of the pQCT outcomes at the $33 \%$ distal radius.

Sensitivity analysis: reduced models—Reduced models with the aBMD and pQCT outcomes were created to confirm FSH was non-significant given only FSH, lean mass and fat mass included as independent variables. Since the error degrees of freedom is reduced with each independent variable that is added to a model, the reduced models would theoretically have slightly greater power to detect associations if they exist.

Statistical analyses were performed using the Stata SE 9.2 software [14]. We used the Bonferroni correction for adjusting the significance levels for $\mathrm{p}$ values to correct for multiple comparisons [15]. Using this method, $\mathrm{p}$ values $\leq 0.025, \leq 0.0167, \leq 0.010$ were considered statistically significant for the non-bone (two) outcomes, DXA BMD (three) and pQCT outcomes (five), respectively. P values greater than these thresholds but less than 0.05 were considered nearly significant.

Sample size calculations-The planned sample size of 111 women (previously included 16 hormone users) provided $80 \%$ power to detect a (population) correlation coefficient between two continuous-scaled variables as small (in absolute terms) as 0.26 with two-sided tests of statistical significance at the 0.05 level (e.g., a correlation between FSH and trabecular vBMD of -0.26). In comparison, an unadjusted $r$ value of 0.44 was found in a correlation of bioavailable estradiol and trabecular vBMD in a population-based cohort of women aged 40-59 years [16]. For a correlation of this magnitude, the study provided $99 \%$ power.

\section{RESULTS}

\section{Study population and descriptive analysis}

Participants had a mean age of 57.5 years, were predominantly white (80\%), and were overweight on average (Table 1). Six women had FSH values below the laboratory cut point for normal postmenopausal women (range 11.8-19.0, laboratory cut point <21.5). Because there were no a priori laboratory criteria for study entry and these women otherwise met inclusion and exclusion criteria, they were included in the analysis. Women in the low-FSH subgroup were aged 51 to 60 , had $\mathrm{BMI}>29$ and total E2 concentrations 3.1 to 28 .

Mean FSH was $63.0 \mathrm{mIU} / \mathrm{ml}$ with values varying over a wide range $(11.8-270 \mathrm{mIU} / \mathrm{mL})$. FSH was significantly higher in normal weight women compared with overweight and obese women (mean FSH 89.0 for normal weight vs. $50.2 \mathrm{mIU} / \mathrm{ml}$ for women with BMI $>=25$, $\mathrm{p}<0.001)$. Similarly, bio E2 (0.49 vs. $0.63 \mathrm{ng} / \mathrm{dl}, \mathrm{p}=0.45)$ and bio T ( $2.55 \mathrm{vs.} 3.35 \mathrm{ng} / \mathrm{dl}$, $\mathrm{p}=0.29)$ were lower in normal weight women compared with heavier women, but these differences did not reach statistical significance. Mean BMD was in the normal range (Tscore $\geq-1$ at all sites).

\section{Unadjusted Spearman's correlations}

Lean and fat mass $(r=0.77, \mathrm{p}<0.001)$ were strongly correlated. FSH $(r=-0.70,-0.58$, both $\mathrm{p}<0.001)$, LH ( $\mathrm{r}=-0.62,-0.48$, both $\mathrm{p}<0.001)$ and bio $\mathrm{E} 2(\mathrm{r}=0.42,0.51, \mathrm{p}<0.001)$ were moderately correlated with lean and fat mass respectively (Table 2). Age showed no significant correlation with lean or fat mass while bio $\mathrm{T}$ showed a weak correlation with fat mass $(r=0.24, p<0.02)$. 
Lean mass ( $\mathrm{r}=0.54$ to 0.56 , all $\mathrm{p}<0.001$ ), fat mass ( $\mathrm{r}=0.50$ to 0.56 , all $\mathrm{p}<0.001)$, $\mathrm{FSH}$ ( $\mathrm{r}=$ -0.40 to -0.42 , all $\mathrm{p}<0.001$ ), bio $\mathrm{E} 2(\mathrm{r}=0.30$ to 0.34 , all $\mathrm{p}<0.01)$ and bio $\mathrm{T}(\mathrm{r}=0.21$ to 0.25 , all $\mathrm{p}<0.05$ ) were significantly correlated with spine, femoral neck and total hip aBMD. Lean mass showed moderate correlations with total bone area $(r=0.45, p<0.001)$ and cortical area $(\mathrm{r}=0.45, \mathrm{p}<0.001)$ at the $33 \%$ distal radius. As previously reported [4], FSH, bio E2 and bio $\mathrm{T}($ all $\mathrm{p}<0.01)$ showed significant correlations with trabecular vBMD at the ultradistal radius.

\section{Multivariable analysis with lean mass and fat mass as outcomes}

FSH was independently associated with lean mass (Table 3). Urine NTx had near significant associations with lean and fat mass. No other significant associations were found.

\section{Multivariable analysis with areal BMD outcomes}

Race showed statistically significant associations with femoral neck and total hip aBMD and a near significant association with spine aBMD (Table 4). Urine NTx had near significant associations with femoral neck and total hip aBMD.

\section{Multivariable analysis with pQCT outcomes at the $4 \%$ (ultradistal) and $33 \%$ distal radius}

A significant association was found for urine NTx $(\beta=-0.561, \mathrm{p}=0.003)$ and near-significant associations were found for FSH and LH vs. trabecular vBMD at the ultradistal radius (Table 5).

At the 33\% distal radius, independent associations were found between lean mass ( $\beta=0.819$, $\mathrm{p}=0.008)$ and race $(\beta=-11.094, \mathrm{p}=0.002)$ vs. total bone area, and urine NTx vs. total bone $\operatorname{vBMD}(\beta=-1.672, \mathrm{p}=0.001)$. Race $(\beta=-8.620, \mathrm{p}<0.001)$ and urine NTx $(\beta=-0.147$, $\mathrm{p}=0.001)$ were associated with cortical area and urine NTx $(\beta=-0.544, \mathrm{p}=0.001)$ was associated with cortical vBMD. Near significant associations were found between lean mass vs. cortical area and cortical vBMD at the $33 \%$ distal radius.

In the reduced models, FSH showed significant associations with aBMD at all sites (all $\mathrm{p}<=0.001$ ) when it was the only independent variable. However, FSH showed no significant association with any aBMD or pQCT measure when FSH and lean mass or FSH and fat mass were the independent variables.

\section{DISCUSSION}

This cross-sectional study of postmenopausal women aged 50 to 64 years recruited from primary care practices showed FSH was independently associated with lean mass, but not with DXA and pQCT measures of BMD. These results suggest that prior unadjusted associations between FSH and BMD were not due to a direct effect of FSH on bone. Instead, higher FSH concentration was a marker of lower lean mass that was independently associated with smaller bone area at the $33 \%$ distal radius. Although race showed no significant association with lean or fat mass, it showed independent associations with aBMD measures and bone area.

Our results are consistent with Drake et al's interventional study demonstrating that suppression of FSH secretion did not reduce levels of bone resorption markers in postmenopausal women [3]. Importantly, they selected a cohort that was clearly past the menopausal transition, in whom levels of hormonal confounders such as progesterone and inhibin A and B would be stable and low. Because conflicting data exist regarding whether associations between FSH and BMD are [17] or are not [1] at least partially estrogen- 
independent, we agree that the separation of pre- and postmenopausal participants is essential in studies of this type.

We found an independent association for lean mass vs. total bone area, but not lean mass vs. aBMD or vBMD. This suggests that the effect of lean mass on bone was an increase in bone size, which might not necessarily be reflected by an increase in aBMD. Also, a past crosssectional comparison found that after correcting for fat-free mass, peripheral muscle strength measures were lower in obese women compared to lean women [18]. In our cohort with a high proportion of obese participants (36 [38\%] with BMI >=30), higher body weight correlated with higher lean mass, but it is possible that lean mass effects on BMD were more difficult to detect because of low muscle strength and deconditioning in heavyset women. Our findings also support that race influences aBMD and cortical area independently, not only through weight or body composition. The independent associations we found between urine NTx and total and cortical vBMD are consistent with past studies of urine NTx as a sensitive biomarker of BMD loss [19, 20].

The lack of an independent association between bio E2, bio $\mathrm{T}$ and other hormonal factors vs. BMD in our analysis suggests hormonal effects are less important than the weight-bearing effect of increased lean and fat mass on bone. Accordingly, we found independent associations for weight but not hormonal measures vs. aBMD in an analysis of a similar cohort [4]. We acknowledge that the predominance of weight-bearing effects over hormonal factors in our studies might be characteristic of heavier women, since the mean BMI of our participants was at the lower threshold for obesity.

Our results should be interpreted in light of several limitations. Our study has cross-sectional design, which can never confirm cause/effect or a mechanistic pathway. In particular, inconsistent and contradictory research findings occur often in hormonal studies due to many confounding physiological influences [21]. Confounding can be caused by variables that are associated with both outcome and exposure and are not on the causal pathway between exposure and outcome. In our analysis, lean mass may be associated with both FSH and BMD, but is not an intermediate step in a "causal" pathway." Controlling for confounders may decrease bias, but this process can still be problematic due to measurement error of the confounder included in the model (residual confounding) [22]. Unmeasured confounding due to omission of a confounder from the model can also be a source of misleading results. This could be present in our analysis due to the absence of inhibins, progesterone or other hormonal factors in our models; however, the effects of such factors are likely to be weak compared to sex hormones, which were included in our multivariable analysis but did not show independent associations with BMD. Further prospective analysis would be needed to confirm whether FSH is associated with change in lean mass over time in postmenopausal women, and whether this relationship influences BMD. Dietary and physical activity measures would also be important in a prospective study, since these factors may modify changes in body composition and BMD [23]. Although six women in the cohort had FSH values below the lab threshold for postmenopausal, their clinical histories (e.g., four were aged 55 to 60, one had history of bilateral ovariectomy) were consistent with postmenopausal status, so their low FSH might have been associated with obesity as has been reported by DePergola [5].

Although our results may help explain previous conflicting findings regarding FSH and $\mathrm{BMD}$, they are unlikely to change clinical assessment of osteoporosis risk. Weight is a key predictor of osteoporosis [24-27] and bone loss [28-30] in postmenopausal women, and is strongly correlated with both lean mass and fat mass ( $\mathrm{r}=0.94$ for weight vs. lean mass and $\mathrm{r}=0.91$ for weight vs. fat mass in our analysis). Weight and age have consistently been found to be the most important clinical risk factors for osteoporosis in postmenopausal women [24, 
$26,27]$. Weight is an easily measured parameter that is routinely assessed in clinics, and can be used to assess osteoporosis risk in nearly any patient. Our findings support the use of weight for osteoporosis risk stratification without the need for concurrent measurement of non-bone body composition or hormonal factors.

In conclusion, FSH was independently associated with lean mass but not BMD measured by DXA or pQCT. Correlations between FSH and BMD might reflect weight-bearing and nonweight-bearing effects of greater lean mass and weight on BMD.

\section{Acknowledgments}

We acknowledge Brent Henderson for his assistance with data collection and database management, and Dan Schiferl of Bone Diagnostic Inc. for his training and supervision of the pQCT analysis.

Grant support: The project described was funded by the National Institute of Arthritis and Musculoskeletal and Skin Diseases (Grant number R03AR055734) and the National Center for Research Resources (Grant numbers K23RR024685, M01RR00046 and UL1RR025747). ). The content is solely the responsibility of the authors and does not necessarily reflect the official views of the funding agencies.

\section{REFERENCES}

[1]. Sun L, Peng Y, Sharrow A, Iqbal J, Zhang Z, Papachristou D, Zaidi S, Zhu L-L, Yaroslavskiy B, Zhou H, Zallone A, Sairam M, Kumar T, Bo W, Braun J, Cardoso-Landa L, Schaffler M, Moonga B, Blair H, Zaidi M. FSH directly regulates bone mass. Cell. 2006; 125:247-260. [PubMed: 16630814]

[2]. Gao J, Tiwari-Pandey R, Samadfam R, Yang Y, Miao D, Karaplis A, Sairam M, Goltzman D. Altered ovarian function affects skeletal homeostasis independent of the action of folliclestimulating hormone. Endocrinology. 2007; 148:2613-2621. [PubMed: 17332067]

[3]. Drake MT, McCready LK, Hoey KA, Atkinson EJ, Khosla S. Effects of suppression of folliclestimulating hormone secretion on bone resorption markers in postmenopausal women. J Clin Endocrinol Metab. 2010; 95:5063-8. [PubMed: 20610587]

[4]. Gourlay ML, Preisser JS, Hammett-Stabler CA, Renner JB, Rubin J. Follicle-stimulating hormone and bioavailable estradiol are less important than weight and race in determining bone density in younger postmenopausal women. Osteoporos Int. 2011; 22:2699-708. [PubMed: 21125395]

[5]. De Pergola G, Maldera S, Tartagni M, Pannacciulli N, Loverro G, Giorgino R. Inhibitory effect of obesity on gonadotropin, estradiol, and inhibin B levels in fertile women. Obesity (Silver Spring). 2006; 14:1954-60. [PubMed: 17135611]

[6]. Sowers M, Zheng H, Tomey K, Karvonen-Gutierrez C, Jannausch M, Li X, Yosef M, Symons J. Changes in body composition in women over six years at midlife: ovarian and chronological aging. J Clin Endocrinol Metab. 2007; 92:895-901. [PubMed: 17192296]

[7]. Cannon JG, Cortez-Cooper M, Meaders E, Stallings J, Haddow S, Kraj B, Sloan G, Mulloy A. Follicle-stimulating hormone, interleukin-1, and bone density in adult women. Am J Physiol Regul Integr Comp Physiol. 2010; 298:R790-8. [PubMed: 20042686]

[8]. Pluijm SM, Visser M, Smit JH, Popp-Snijders C, Roos JC, Lips P. Determinants of bone mineral density in older men and women: body composition as mediator. J Bone Miner Res. 2001; 16:2142-51. [PubMed: 11697812]

[9]. Douchi T, Yamamoto S, Oki T, Maruta K, Kuwahata R, Yamasaki H, Nagata Y. Difference in the effect of adiposity on bone density between pre- and postmenopausal women. Maturitas. 2000; 34:261-6. [PubMed: 10717492]

[10]. Aloia JF, Vaswani A, Ma R, Flaster E. To what extent is bone mass determined by fat-free or fat mass? Am J Clin Nutr. 1995; 61:1110-4. [PubMed: 7733036]

[11]. Gnudi S, Sitta E, Fiumi N. Relationship between body composition and bone mineral density in women with and without osteoporosis: relative contribution of lean and fat mass. J Bone Miner Metab. 2007; 25:326-32. [PubMed: 17704998] 
[12]. Compston JE, Bhambhani M, Laskey MA, Murphy S, Khaw KT. Body composition and bone mass in post-menopausal women. Clin Endocrinol (Oxf). 1992; 37:426-31. [PubMed: 1486693]

[13]. Khosla S, Melton L, Atkinson E, O’Fallon W, Klee G, Riggs B. Relationship of serum sex steroid levels and bone turnover markers with bone mineral density in men and women: a key role for bioavailable estrogen. J Clin Endocrinol Metab. 1998; 83:2266-2274. [PubMed: 9661593]

[14]. StataCorp. Stata Statistical Software: Release SE 9.2. College Station; 2005.

[15]. Bland J, Altman D. Multiple significance tests: the Bonferroni method. BMJ. 1995; 310:170. [PubMed: 7833759]

[16]. Khosla S, Riggs B, Robb R, Camp J, Achenbach S, Oberg A, Rouleau P, Melton Lr. Relationship of volumetric bone density and structural parameters at different skeletal sites to sex steroid levels in women. J Clin Endocrinol Metab. 2005; 90:5096-103. [PubMed: 15998772]

[17]. Allan CM, Kalak R, Dunstan CR, McTavish KJ, Zhou H, Handelsman DJ, Seibel MJ. Folliclestimulating hormone increases bone mass in female mice. Proc Natl Acad Sci U S A. 2010; 107:22629-34. [PubMed: 21149714]

[18]. Hulens M, Vansant G, Lysens R, Claessens AL, Muls E, Brumagne S. Study of differences in peripheral muscle strength of lean versus obese women: an allometric approach. Int J Obes Relat Metab Disord. 2001; 25:676-81. [PubMed: 11360150]

[19]. Chaki O, Yoshikata I, Kikuchi R, Nakayama M, Uchiyama Y, Hirahara F, Gorai I. The predictive value of biochemical markers of bone turnover for bone mineral density in postmenopausal Japanese women. J Bone Miner Res. 2000; 15:1537-44. [PubMed: 10934652]

[20]. Gorai I, Taguchi Y, Chaki O, Nakayama M, Minaguchi H. Specific changes of urinary excretion of cross-linked N-telopeptides of type I collagen in pre- and postmenopausal women: correlation with other markers of bone turnover. Calcif Tissue Int. 1997; 60:317-22. [PubMed: 9075625]

[21]. Tremblay MS, Chu SY, Mureika R. Methodological and statistical considerations for exerciserelated hormone evaluations. Sports Med. 1995; 20:90-108. [PubMed: 7481285]

[22]. Fewell Z, Smith G Davey, Sterne JA. The impact of residual and unmeasured confounding in epidemiologic studies: a simulation study. Am J Epidemiol. 2007; 166:646-55. [PubMed: 17615092]

[23]. Villareal DT, Chode S, Parimi N, Sinacore DR, Hilton T, Armamento-Villareal R, Napoli N, Qualls C, Shah K. Weight loss, exercise, or both and physical function in obese older adults. N Engl J Med. 2011; 364:1218-29. [PubMed: 21449785]

[24]. Wildner M, Peters A, Raghuvanshi V, Hohnloser J, Siebert U. Superiority of age and weight as variables in predicting osteoporosis in postmenopausal white women. Osteoporos Int. 2003; 14:950-956. [PubMed: 13680102]

[25]. Zhai G, Hart D, Valdes A, Kato B, Richards J, Hakim A, Spector T. Natural history and risk factors for bone loss in postmenopausal Caucasian women: a 15-year follow-up population-based study. Osteoporos Int. 2008; 19:1211-1217. [PubMed: 18305885]

[26]. Koh L, Sedrine W Ben, Torralba T, Kung A, Fujiwara S, Chan S, Huang Q, Rajatanavin R, Tsai K, Park H, Reginster J-Y. A simiple tool to identify Asian women at increased risk of osteoporosis. Osteoporos Int. 2001; 12:699-705. [PubMed: 11580084]

[27]. Waugh E, Lam M, Hawker G, McGowan J, Papaioannou A, Cheung A, Hodsman A, Leslie W, Simonoski K, Jamal S. Risk factors for low bone mass in healthy 40-60 year old women: a systematic review of the literature. Osteoporos Int. 2009; 10:1-21. [PubMed: 18523710]

[28]. Macdonald H, New S, Campbell M, Reid D. Influence of weight and weight change on bone loss in perimenopausal and early postmenopausal Scottish women. Osteoporos Int. 2005; 16:163171. [PubMed: 15185065]

[29]. May H, Murphy S, Khaw K-T. Age-associated bone loss in men and women and its relationship to weight. Age and Aging. 1994; 23:235-240.

[30]. Harris S, Dallal G, Dawson-Hughes B. Influence of body weight on rates of change in bone density of the spine, hip, and radius in postmenopausal women. Calcif Tissue Int. 1992; 50:1923. [PubMed: 1739865] 
Research highlights for Gourlay et al, "Follicle-stimulating hormone is independently associated with lean mass but not BMD in younger postmenopausal women"

- Higher FSH levels were independently associated with lower lean mass but not with BMD.

- Correlations between FSH and BMD might be due to confounding by lean mass or weight.

- Hormonal effects may be less important than the weight-bearing effect of body mass on bone. 
Table 1

Subject characteristics $(\mathrm{n}=94)$

\begin{tabular}{|c|c|}
\hline $\begin{array}{l}\text { Characteristic } \\
\text { Age, y }\end{array}$ & $\begin{array}{c}\text { Mean (SD) or n }(\%) \\
57.6(3.6)\end{array}$ \\
\hline $\begin{array}{l}\text { Weight, } \mathrm{kg} \\
\text { range }\end{array}$ & $\begin{array}{l}80.3(21.0) \\
46.8-137.2\end{array}$ \\
\hline $\begin{array}{l}\mathrm{BMI}\left(\mathrm{kg} / \mathrm{m}^{2}\right) \\
\text { range }\end{array}$ & $\begin{array}{l}29.9(7.7) \\
18.7-49.2\end{array}$ \\
\hline Fat-free lean mass $(\mathrm{kg})$ & $45.1(8.5)$ \\
\hline Fat mass $(\mathrm{kg})$ & $30.9(12.7)$ \\
\hline \multicolumn{2}{|l|}{ Ethnicity/race, n \% } \\
\hline White & $67(70.5)$ \\
\hline Black & $24(25.3)$ \\
\hline Other & $4(4.2)$ \\
\hline Years since menopause & $11.2(9.3)$ \\
\hline Had a hysterectomy, n \% & $36(37.9)$ \\
\hline Ever use of hormone therapy, $\mathrm{n} \%$ & $52(54.7)$ \\
\hline Current use of hormone therapy, $\mathrm{n} \%$ & 0 \\
\hline $\mathrm{FSH}, \mathrm{mIU} / \mathrm{ml}$ & $\begin{array}{c}63.0(35.1) \\
\text { range } 11.8-270\end{array}$ \\
\hline Bio E2, ng/dl & $\begin{array}{c}0.58(0.83) \\
\text { range } 0-6.61\end{array}$ \\
\hline Bio $\mathrm{T}, \mathrm{ng} / \mathrm{dl}$ & $3.09(3.45)$ \\
\hline $\mathrm{SHBG}, \mathrm{nmol} / \mathrm{L}$ & $41.1(22.6)$ \\
\hline Urine NTx ( nmol bce/mmol urine creatinine) & $42.2(22.8)$ \\
\hline \multicolumn{2}{|l|}{ Lumbar spine DXA } \\
\hline $\mathrm{aBMD}, \mathrm{g} / \mathrm{cm}^{2}$ & $1.018(0.137)$ \\
\hline T-score & $-0.46(1.17)$ \\
\hline Z-score & $0.81(1.20)$ \\
\hline \multicolumn{2}{|l|}{ Femoral neck DXA } \\
\hline $\mathrm{aBMD}, \mathrm{g} / \mathrm{cm}^{2}$ & $0.775(0.138)$ \\
\hline T-score & $-0.84(1.05)$ \\
\hline Z-score & $0.26(1.01)$ \\
\hline \multicolumn{2}{|l|}{ Total hip DXA } \\
\hline $\mathrm{aBMD}, \mathrm{g} / \mathrm{cm}^{2}$ & $0.890(0.136)$ \\
\hline
\end{tabular}




\begin{tabular}{|l|c|}
\hline Characteristic & $\begin{array}{c}\text { Mean }(\mathrm{SD}) \text { or n }(\%) \\
-0.57(0.95) \\
\text { T-score }\end{array}$ \\
Z-score & $0.21(0.93)$ \\
\hline $4 \%$ distal radius, trabecular vBMD $\left(\mathrm{mg} / \mathrm{cm}^{3}\right)$ & $199.2(39.7)$ \\
\hline $33 \%$ distal radius & \\
Total bone area $\left(\mathrm{mm}^{2}\right)$ & $93.9(14.6)$ \\
Total vBMD $\left(\mathrm{mg} / \mathrm{cm}^{3}\right)$ & $1011.2(99.0)$ \\
Cortical area $\left.(\mathrm{mm})^{2}\right)$ & $74.5(10.1)$ \\
Cortical vBMD $\left(\mathrm{mg} / \mathrm{cm}^{3}\right)$ & $1217.0(31.4)$ \\
\hline
\end{tabular}

aBMD=areal bone mineral density vBMD=volumetric bone mineral density normal values for postmenopausal women: FSH $21.5-131 \mathrm{mIU} / \mathrm{ml}$ (see text re participants with FSH <21.5); total E2 <15 pg/ml; bio E2 not available from reference laboratories; bio T not established; SHBG 20-130 $\mathrm{nmol} / \mathrm{L}$ 


\begin{tabular}{|c|c|c|c|c|c|c|c|c|}
\hline 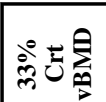 & $\frac{9}{i}$ & $\begin{array}{l}m \\
0 \\
0\end{array}$ & $\frac{\sigma}{0}$ & $\begin{array}{l}\hat{0} \\
\dot{i}\end{array}$ & $\bar{\Xi}$ & $\stackrel{\leftrightarrow}{\circ}$ & 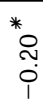 & $\begin{array}{l}+w \\
0 \\
0 \\
0 \\
0\end{array}$ \\
\hline CొE & 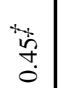 & 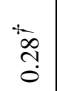 & $\frac{0}{0}$ & : & 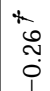 & $\stackrel{\circ}{0}$ & $\stackrel{0}{0}$ & \\
\hline
\end{tabular}

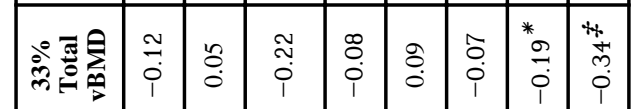

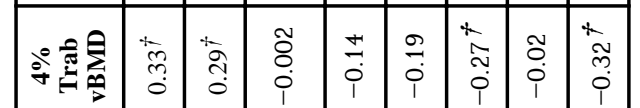

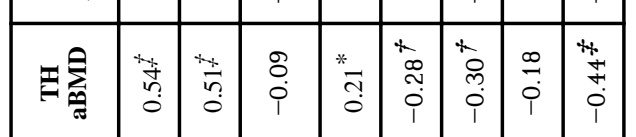

(

离

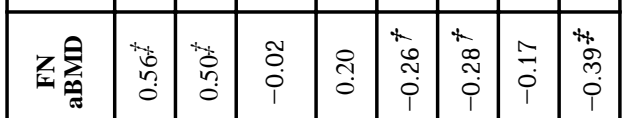

D o

एँ

势

若

这

过

ฮี

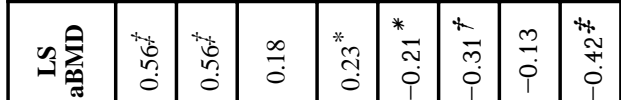

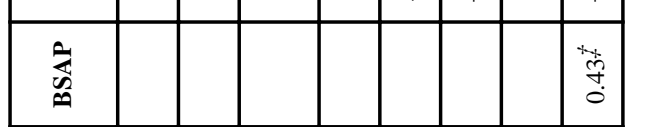

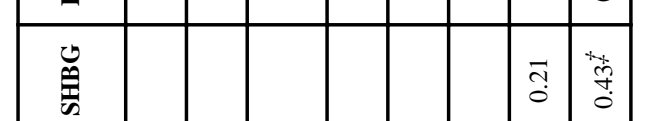

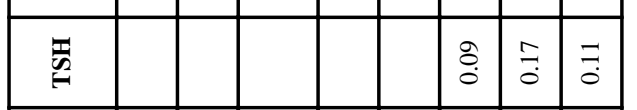

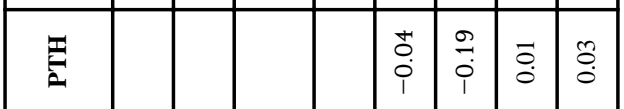

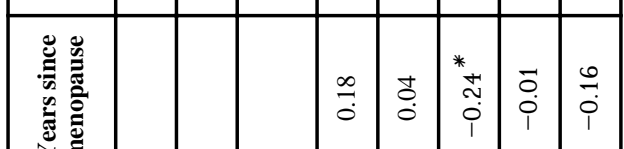

窇亖

สิ

ฮี่

के

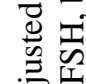

\begin{tabular}{|c|c|c|c|c|c|c|c|c|}
\hline 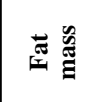 & & & $\frac{\infty}{0}$ & * & $\begin{array}{l}0 \\
\stackrel{0}{1} \\
1\end{array}$ & $\begin{array}{l}\text { th } \\
\text { o } \\
0 \\
0\end{array}$ & $\begin{array}{l}\overline{0} \\
i\end{array}$ & \\
\hline 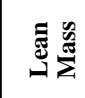 & & 答 & $\frac{9}{0}$ & $\begin{array}{l}\text { io } \\
\text { a } \\
0\end{array}$ & $\stackrel{m}{0}$ & $\begin{array}{l}40 \\
5 \\
0 \\
0 \\
0\end{array}$ & $\begin{array}{l}n \\
0 \\
0 \\
1\end{array}$ & \\
\hline & 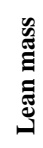 &  & 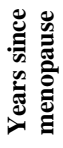 & 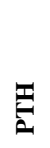 & t: & 曾 & $\overrightarrow{\vec{x}_{0}}$ & \\
\hline
\end{tabular}




\section{Table 3}

Beta coefficients for independent associations in adjusted models of non-bone body composition measures $(n=94)$

\begin{tabular}{|l|c|c|}
\hline Independent variable & \multicolumn{2}{|c|}{ Beta coefficient (95\% CI) } \\
\hline & Lean Mass $(\mathbf{k g})$ & Fat mass (kg) \\
\hline${\text { Age, } \mathrm{y}^{*}}^{*}$ & $-2.602(-6.913,1.709)$ & $-2.009(-8.994,4.976)$ \\
\hline Race & $0.141(-3.138,3.420)$ & $1.242(-4.072,6.555)$ \\
\hline Years since menopause ${ }^{*}$ & $1.492(-.051,3.034)$ & $1.008(-1.492,3.507)$ \\
\hline FSH, mIU/ml & $-0.099(-0.168,-0.030)^{\ddagger}$ & $-0.105(-0.216,-0.007)$ \\
\hline Bioavailable estradiol, ng/dl & $1.011(-0.798,2.820)$ & $2.586(-0.346,5.519)$ \\
\hline Bioavailable testosterone, ng/dL & $-0.128(-0.593,0.336)$ & $-0.410(-1.162,0.342)$ \\
\hline LH, mIU/ml & $-0.036(-0.167,0.095)$ & $-0.042(-0.038,0.193)$ \\
\hline PTH, pg/ml & $0.052(-0.019,0.124)$ & $0.078(-0.038,0.193)$ \\
\hline SHBG, nmol/L & $-0.042(-0.125,0.041)$ & $-0.131(-0.265,0.003)$ \\
\hline Urine NTx ( nmol bce/mmol urine creatinine) & $-0.075(-0.146,-0.004)$ & $-0.117(-0.232,-0.002)$ \\
\hline
\end{tabular}

vBMD volumetric bone mineral density in $\mathrm{mg} / \mathrm{cm}^{3} \mathrm{CI}$ confidence interval

age and years since menopause divided by ten

${ }^{\dagger} 0.025<\mathrm{p}<0.05$

${ }^{*} \mathrm{p}<=0.025$ 
Table 4

Beta coefficients for independent associations in adjusted models of BMD ( $\mathrm{n}=94)$

\begin{tabular}{|l|c|c|c|}
\hline Independent variable & \multicolumn{3}{|c|}{ Beta coefficient (95\% CI) } \\
\hline & Spine aBMD & Femoral neck aBMD & Total hip aBMD \\
\hline Age, ${ }^{*}$ & $0.029(-0.040,0.098)$ & $-0.047(-0.115,0.021)$ & $-0.037(-0.105,0.031)$ \\
\hline Lean mass, kg & $0.005(-0.0001,0.009)$ & $0.003(-0.002,0.008)$ & $0.001(-0.003,0.006)$ \\
\hline Fat mass, kg & $0.003(-0.0002,0.006)$ & $0.002(-0.001,0.005)$ & $0.003(-0.0003,0.006)$ \\
\hline Race & $-0.062(-0.116,-0.007)$ & $-0.106(-0.160,-0.052)^{\ddagger}$ & $-0.080(-0.133,-0.026)^{\ddagger}$ \\
\hline FSH, $\mathrm{mIU} / \mathrm{ml}$ & $-0.0002(-0.001,0.001)$ & $-0.0003(-0.001,0.001)$ & $-0.0006(-0.002,0.001)$ \\
\hline Bio E2, ng/dl & $0.011(-0.042,0.021)$ & $0.007(-0.024,0.039)$ & $0.008(-0.023,0.039)$ \\
\hline Bio T, ng/dL & $0.005(-0.003,0.013)$ & $-0.003(-0.010,0.005)$ & $-0.0004(-0.008,0.007)$ \\
\hline LH, $\mathrm{mIU} / \mathrm{ml}$ & $0.0006(-0.002,0.003)$ & $0.001(-0.001,0.003)$ & $0.001(-0.001,0.003)$ \\
\hline SHBG, nmol/L & $0.0004(-0.001,0.002)$ & $-0.0004(-0.002,0.001)$ & $-0.0006(-0.002,0.0008)$ \\
\hline $\begin{array}{l}\text { Urine NTx }(\mathrm{nmol} \mathrm{bce} / \\
\text { mmol urine creatinine })\end{array}$ & $-0.001(-0.002,0.00005)$ & $-0.001(-0.003,-0.0001)$ & $-0.001(-0.003,-0.0001)^{\dagger}$ \\
\hline
\end{tabular}

aBMD areal bone mineral density in $\mathrm{g} / \mathrm{cm}^{2} \mathrm{CI}$ confidence interval

*age divided by ten

${ }^{\dagger} 0.0167<\mathrm{p}<0.05$

$*_{\mathrm{p}}<=0.0167$ 


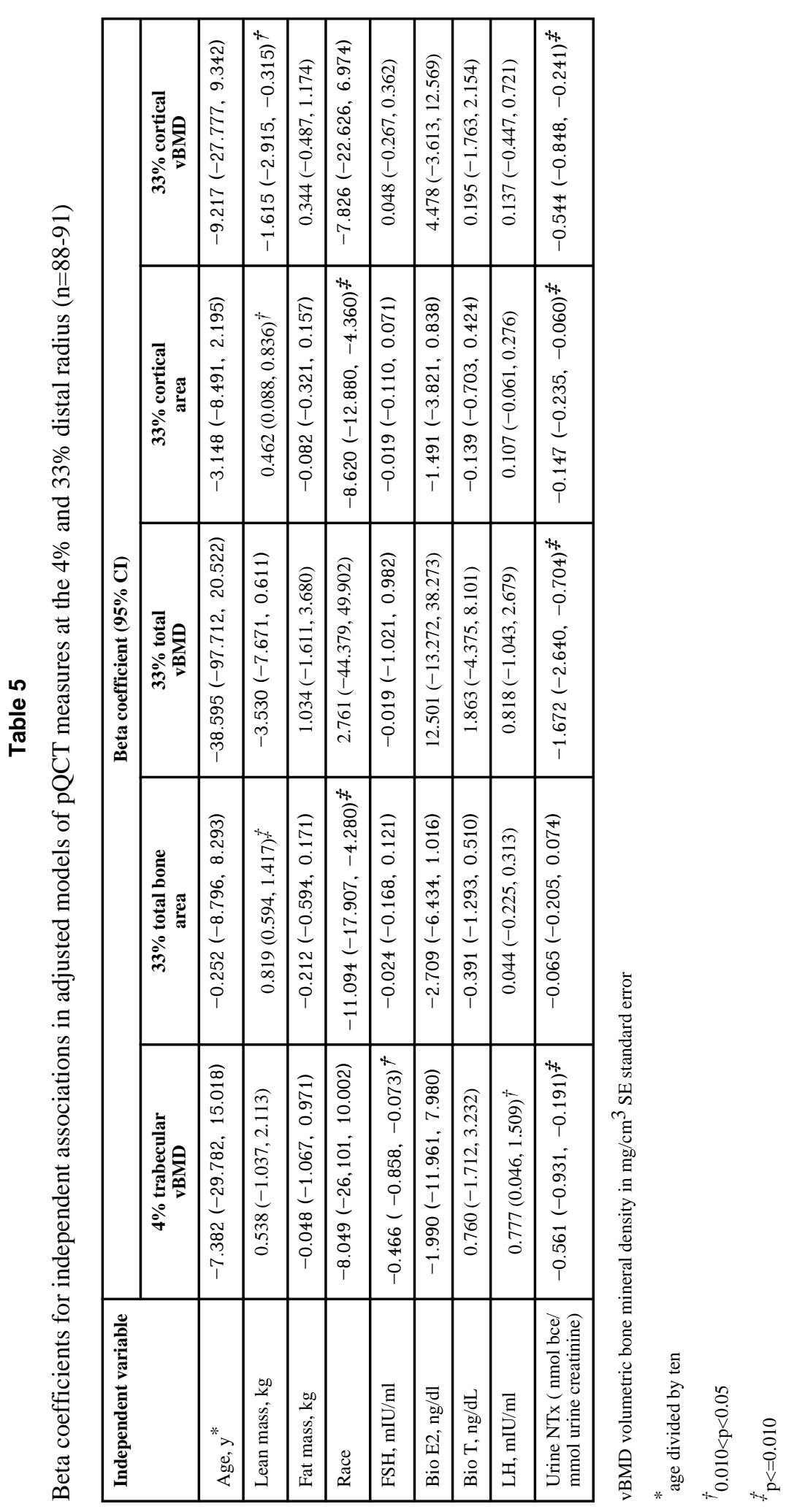

Bone. Author manuscript; available in PMC 2013 January 1. 